\title{
Fault Identification in Sub-station by Using Neuro-Fuzzy Technique
}

\author{
Anirudh Yadav ${ }^{1}$, Vinay Kumar Harit ${ }^{2}$ \\ ${ }^{1}$ Department of Electrical Engineering, S.H.I.A.T.S, Allahabad, U.P., India \\ ${ }^{2}$ Department of Electrical Engineering, Delhi Technical University, New Delhi, India
}

\begin{tabular}{l} 
Article Info \\
\hline Article history: \\
Received Sep 16, 2017 \\
Revised Nov 17, 2017 \\
Accepted Nov 22, 2017 \\
\hline Keyword: \\
Artificial neural network \\
(ANN) \\
Fuzzy logic (FL) \\
Graphical user interface (GUI) \\
Substation
\end{tabular}

\begin{abstract}
Fault identification and its diagnosis is an important issue in present scenario of power system, as huge amount of electric power is utilized. Random types of faults occur in substation, which leads to irregular and discontinue supply of power from generating to consumer point. Fault detection is an important concept of power system which is to be studied and new method has to develop for fault detection and removal of it. This paper proposed on-line fault detection and identification of fault-type by using Neuro-Fuzzy method in substation. Combination of Artificial Neural Network (ANN) and Fuzzy Logic (FL), results in gaining learning capabilities of fuzzy logic. Variation of current according to fault is used for identification. Fuzzy controller display output condition in form of $(0,1)$.Here, single line-to ground (LG) fault, line-to-line (LL) fault, double line-to ground (LLG)/LLL fault are considered.
\end{abstract}

Copyright $\odot 2017$ Institute of Advanced Engineering and Science. All rights reserved.

\section{Corresponding Author:}

Anirudh Yadav,

Department of Electrical Engineering, S.H.I.A.T.S, Allahabad, U.P., India.

Email: id-er.anirudh53@gmail.com

\section{INTRODUCTION}

Due to present development in all-around world, consumption and demand of the electric power is increased to large extend. This demand has to meet with the level of quality and without interruptions. A power distribution is a complex process which involves huge generating plants, large length of transmission line and different level of substations. In this whole process of electric power transfer, voltage is step-up/stepdown at different level as per requirement. For example, electric power is normally generated in range of 11$25 \mathrm{KV}$ in power station. Then it is step-up to HV/EHV/UHV levels $(33 / 66 \mathrm{KV})$ for transmitting power through transmission line for long distance. These lines are terminating into substation at the voltage level of $22 \mathrm{KV} / 11 \mathrm{KV} / 6.6 \mathrm{KV}$ etc for power distribution to load points through a distribution network of lines. At load point (localities, industrial area ,village etc.), a transformer further reduces the voltage level to $415 \mathrm{~V}$ to provide the supply to low tension (LT) feeders to individuals consumer, either at $240 \mathrm{~V}$ (for single phase supply) or $415 \mathrm{~V}$ (for three-phase supple). An overhead line or an underground cable is used in feeder. Depending upon density of consumers, length of $11 \mathrm{KV}$ feeder is generally up to $3 \mathrm{~km}$ in urban area while length is much larger (up to $20-30 \mathrm{~km}$ ) in rural areas. Thus, it is necessary to have fault handling system for continuous and reliable electric power supply.

Integrating of Artificial neuron Network (ANN) and fuzzy logic (FL), called Neuro-fuzzy networks. In this network, output or weight of ANN serves as fuzzy sets and it have neuron that called fuzzy neurons. Variation of current, according to fault is used for identification. Fuzzy controller display output condition in form of $(0,1)$ i.e. 0 for normal condition and 1 for fault condition. 


\section{SUBSTATION}

A supplementary station for electricity generation, transmission and distribution system where voltage level is step-up/step-down with the help of transformer. Depending upon voltage, their application in power system and method used to build them, these substation are classified in various types like transmission substations, distribution substation, Converter substation, switching substations etc. Some of the elements of substation are shown in Figure 2 (a).

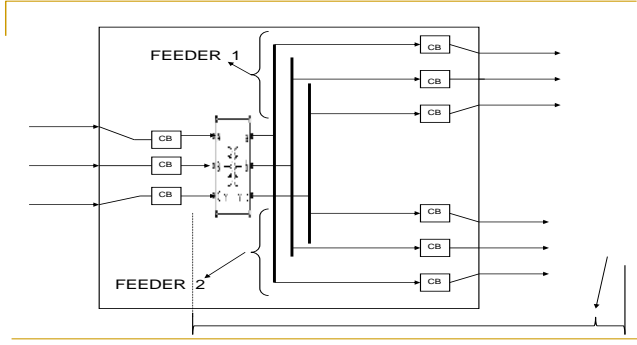

Figure 2 (a). Layout of Substation

Substations consist of switching and protection system, transformers, relays, circuit breakers feeders for supply electric power to small area. They may be on the surface in fenced enclosures, underground or located in special-purpose building.

Feeder of Substation it is uneconomical and non-reliable to connect the consumers to the highvoltage transmission line network directly, if they not require huge amounts of power. So, the distribution substation reduces voltage level to a suitable for local consumers like small industries, houses etc which fed by using feeders. The feeders of substation are short in length.

\section{FAULT}

Abnormal conditions occur while transmitting power is called electrical faults. They are categorized into Symmetrical faults and Unsymmetrical faults. Again, Unsymmetrical faults are classified as Single lineto ground (LG) fault, line-to-line (LG) fault and double line/LLL-ground fault. Out of all faults, LG fault is most severe. According to faults, various waveforms showing variation of current are:

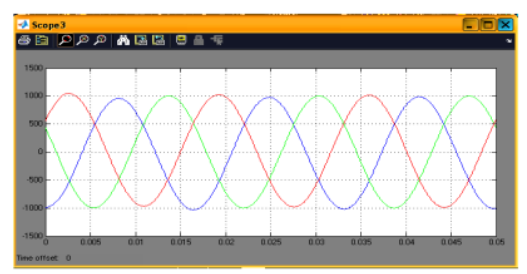

Figure 3. (a) Waveform of Current at No-fault Condition

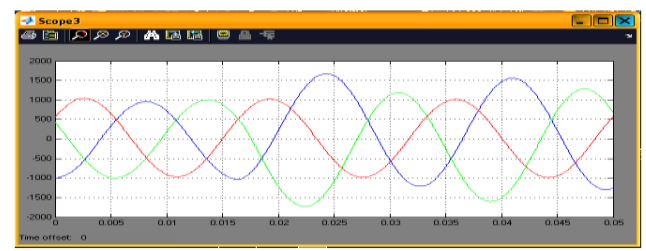

Figure 3 (c). Waveform of Current at LL Fault Condition

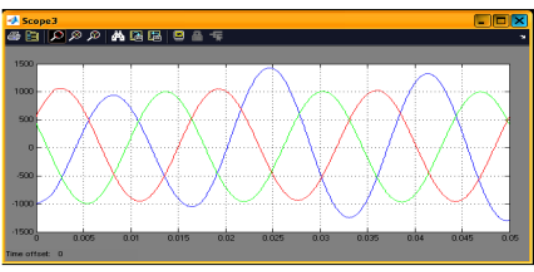

Figure 3 (b). Waveform of Current at LG Fault Condition

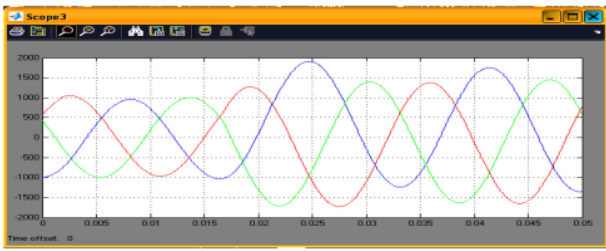

Figure 3 (d). Waveform of current at LLL fault 


\section{ARTIFICIAL NEURAL NETWORK (ANN)}

An artificial neuron network which depend on relationship between past, present and future condition held in any system. These networks consist of input nodes or input layer if neurons, one or more hidden layer of neurons, and final layer of output neurons. Numerical value which is associated to each connection is called weight. This network is composed of simple element operating in parallel.

Some factor which give advantage to ANN:

a. These networks are non-linear which make able to classify between different patterns.

b. These are adaptive, can take data and learn from it.

c. They can be easily generalized

d. ANN is a parallel distributed information processing network.

\subsection{Artificial Neuron Model}

Here, processing neuron computes the weighted sum of its inputs and output according to whether this weighted sum is above or below a certain threshold. This model is governed by Equation:

$$
\begin{aligned}
& \mathrm{y}_{\mathrm{k}}=\mathrm{f}\left(\mathrm{u}_{\mathrm{k}}-\theta_{\mathrm{k}}\right) \quad \ldots \ldots .(\mathrm{i}) \quad \text { where } \mathrm{u}_{\mathrm{k}}=\sum \mathrm{w}_{\mathrm{kj}} \mathrm{x}_{\mathrm{j}} \\
& \mathrm{x}_{1}, \mathrm{x}_{2}, \mathrm{x}_{3, \ldots \ldots \ldots . . .} \mathrm{x}_{\mathrm{p}}-\text { Input signal } \\
& \mathrm{w}_{\mathrm{k} 1}, \mathrm{w}_{\mathrm{k} 2}, \ldots \ldots . \mathrm{w}_{\mathrm{kp}}-\text { Weight of neuron } \mathrm{k} \\
& \mathrm{u}_{\mathrm{k}}-\text { linearly combined output }
\end{aligned}
$$

\subsection{Learning in ANN}

Different learning process are used which depend upon compatibility to different task. A neural network uses either supervised or unsupervised learning.

\subsubsection{Supervised learning}

In supervised learning, the network which is provided with example and desired output is obtained. Then network weight is modified to minimize the difference between network output and desired output.

\subsubsection{Unsupervised learning}

An input signal is only given in unsupervised learning, and the network weight is change through predefined algorithm, which usually groups the data into bundle of same information. A feed forward network is most common network used for supervised learning. Multi-layer Perception (MLP) network is most popular of all neuron network. MLP is most popular neural network type which is used and generally short-term load forecasting model are based on it. A perceptron is the basic neuron (unit) of the network. The MLP network consists of several layers of neurons. Each neuron in a particular layer is connected to each neuron of other layer. Feedback connections are absent.

\subsection{Architecture of ANN model}

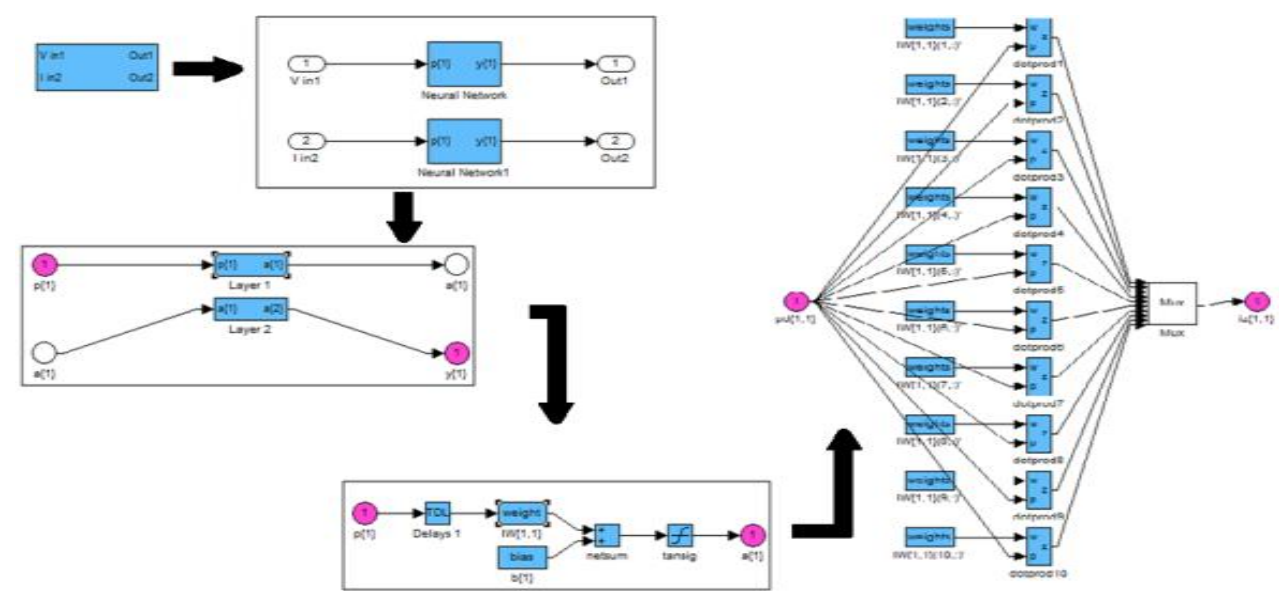

Figure 4 (a). Architecture of ANN Model 


\subsection{ANN in MATLAB}

A neural network can trained to perform a particular function by adjusting the values of the weights between elements. The training of ANN in MATLAB is done by using graphical tools to solve problems in function fitting, pattern recognition and clustering. Graphical User Interface (GUI) is designed to be simple and user friendly. GUI are use for creating function in ANN. The following functions are:

a. nctool-Neural network classification tool

b. nftool-Open Neural Network fitting tool

c. nntool-Open Network/Data Manager

d. nntraintool- Neural Network training tool

e. nprtool-Network pattern recognition tool

f. view-View a neural network

In all function,"nftool" function is used to create the ANN model.

\section{FUZZY LOGIC}

In 1960, Lotfi A. Zeden develops a mathematical rule and functions for providing natural language queries, called fuzzy logic. It is set of conventional or Boolean logic. It provide a method of calculate intermediate values between absolute true and absolute false condition within range of $0.0-1.0$. It is possible to calculate the degree to which an item is a member by fuzzy logic.

They provide powerful mathematical tools which help in modeling and controlling $\mathrm{n}$ uncertain system in different fields. Fuzzy sets are facilitators in giving approximate reason in decision-making without complete and precise data. The graphical representation of fuzzy and Boolean sets is different from each other. It also allows giving wide range of application in different fields.

\subsection{Fuzzy Sets}

A set in which whole elements have degree of membership, is a fuzzy sets i.e. an element of set cab be full member or a partial member. Following method is used to define a crisp set:-

a. A subset $U$ of a set $S$ is a mapping from elements of $S$ to the set $\{0,1\}$. This is represented by $\mathrm{U}: \mathrm{S}>\{0,1\}$.

b. A mapping is represented by one ordered pair for each element $S$ where the first element is from the set $\mathrm{S}$ and the second element from set $\{0,1\}$. The value zero represents non-membership and value 1 represent membership.

\subsection{Membership function}

A mathematical function which defines the degree of an element's membership in fussy set is called membership function. For any set $\mathrm{X}$, a membership function on $\mathrm{X}$ is any function from $\mathrm{X}$ to the real unit interval $[0,1]$. It can represent a fuzzy set $\AA$ and denoted by $\mu_{\mathrm{A}}$. Here, output comes in 0,1 form where value 0 means $\mathrm{X}$ in not a member of fuzzy set and value 1 means is member of the fuzzy set. The value between 0 and 1 characterize fuzzy member, which belong to fuzzy set partially.

\subsection{Fuzzy in MATLAB}

Fuzzy Logic Toolbox is a collection if in-built function of MATLAB. It provides tools for creating and editing fuzzy inference system. In fuzzy tool box, GUI is designed to be simple. Following steps is to be taken to create fuzzy logic system:-

a. Type Fuzzy in command window. FIS editor window opens.

b. Click on edit, set input and output. Then set the membership function.

c. Go to edit, click on rule. Rule Editor Window opens. Set the rule according to requirements.

d. After Setting rule, save the window and put Fuzzy logic Controller on model window form Simulink library.

e. Specify our fuzzy inference system as FIL file or structure

f. After that RUN the model and get output according to our rules.

\section{NEURO-FUZZY MODEL}

A combination of ANN and fuzzy logic for artificial intelligence is result in neuro0fuzzy model. It is a linguistic model which uses a set of If-Then fuzzy rules. It is the system which synchronizes two techniques; result in human-like reasoning capability of fuzzy systems with the learning ability of neural 
network. Neuro-fuzzy hybridization is widely termed as Fuzzy Neural Network (FNN) or Neuro-Fuzzy System (NFS).Block diagram representing neuro-fuzzy model shown in Figure 6 (a).

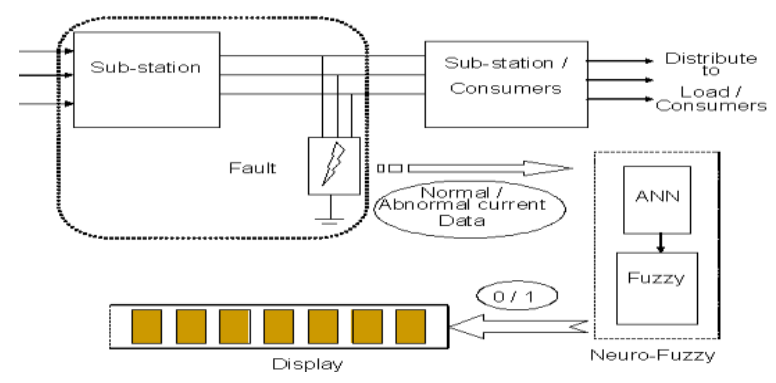

Figure 6 (a). Block Diagram Representing Neuro-fuzzy Model

\section{METHODOLOGY USED}

Figure 7 represents the flowchart used for achieving objective of this work.

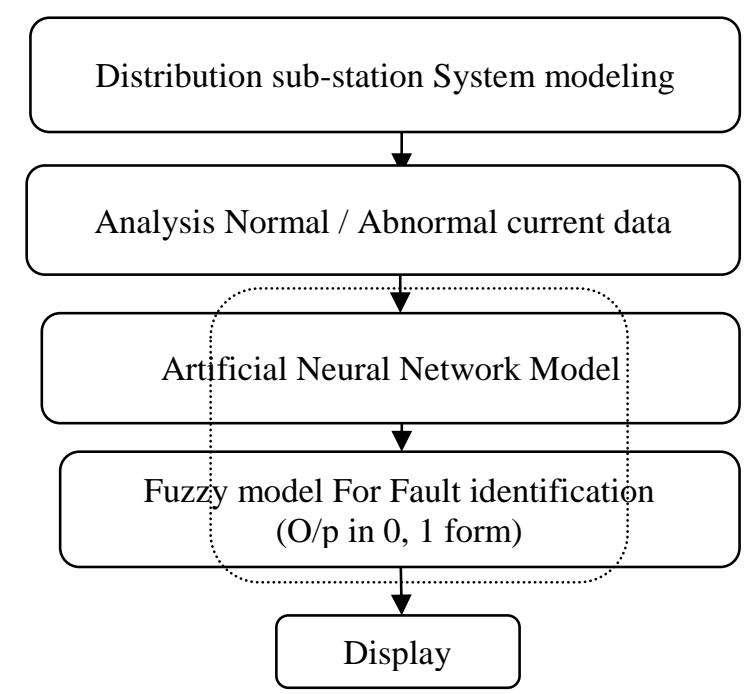

Figure 7. Flow Chart of Model

\section{RESULTS}

In this simulation, the feeder of distribution substation is designed. Here, we identify short circuit fault at substation. A simulate sub-station feeders are shown in Figure 8 (a).

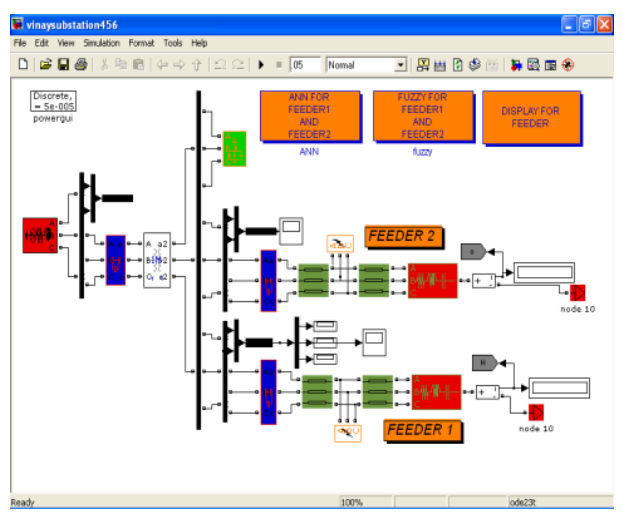

Figure 8 (a). Simulation Block of Substation 
After simulation, we feed the output current to ANN as input. After processing ANN output is used as input for fuzzy logic controller. Finally, fuzzy controller gives output in form $(0,1)$. Various output of Neuro-Fuzzy model is shown below in Tables.

Table 1. Output value of ANN

\begin{tabular}{|c|c|c|c|c|}
\hline & Phase a & Phase b & Phase c & Ground \\
\hline A-g & -2.179 & -4.009 & -4.009 & -2.179 \\
\hline B-g & -4.009 & -2.179 & -4.009 & 1.821 \\
\hline C-g & -4.009 & -4.009 & 1.821 & -2.179 \\
\hline A-B & -2.179 & 1.821 & -4.009 & -4.009 \\
\hline B-C & -4.009 & -2.179 & 1.821 & -4.009 \\
\hline C-A & -2.179 & -4.009 & 1.821 & -4.009 \\
\hline AB-g & -2.179 & 1.821 & -4.009 & -2.195 \\
\hline BC-g & -4.009 & -2.179 & 1.821 & 1.821 \\
\hline CA-g & -2.1279 & -4.009 & 1.821 & -2.179 \\
\hline ABC/ABC-g & -2.179 & -2.179 & 1.821 & -4.009 \\
\hline
\end{tabular}

Table shows the result, when faults occur on Both feeder

Table 3. Output when Fault Occur in Feeder 1

\begin{tabular}{|c|c|}
\hline \multicolumn{2}{|c|}{ O/P of Fuzzy for feeder 1 } \\
\hline A-g & .02438 \\
\hline B-g & .0721 \\
\hline C-g & .2077 \\
\hline A-B & .3142 \\
\hline B-C & .4524 \\
\hline C-A & .5589 \\
\hline AB-g & .6997 \\
\hline BC-g & .8115 \\
\hline CA-g & .9336 \\
\hline ABC/ABC-g & .9841 \\
\hline
\end{tabular}

Table 2. Output of Fuzzy for Single Feeder

\begin{tabular}{|c|c|}
\hline O/P of Fuzzy for Feeder \\
\hline A-g & 03846 \\
\hline B-g & 09791 \\
\hline - $-g$ & 1812 \\
\hline A-B & 2586 \\
\hline B-C & 3518 \\
\hline C-A & 4346 \\
\hline AB-g & 3763 \\
\hline BC-g & 6025 \\
\hline CA-g & 6233 \\
\hline ABC/ABC-g & 806 \\
\hline
\end{tabular}

Table 5. Output Values of Fuzzy, when Faults occur on Both Feeder

\begin{tabular}{|c|c|c|c|c|c|c|c|c|c|c|c|}
\hline F-1 & A-G & B-G & C-G & A-B & B-C & C-A & AB-G & BC-G & CA-G & ABC & ABCG \\
\hline \multirow{2}{*}{ A-G } & .02438 & .09 & .09 & .02438 & .02438 & .02438 & .09 & .09 & .09 & .02438 & .09 \\
& .09 & .7 & .915 & .09 & .8115 & .5 & .6997 & .7 & .9336 & .5 & .5 \\
\hline \multirow{2}{*}{ B-G } & .7 & .0721 & .0721 & .0721 & .0721 & .0721 & .7 & .0721 & .7 & .0721 & .7 \\
& .09 & .7 & .915 & .6997 & .7 & .0336 & .09 & .7 & .5 & .1442 & .5 \\
\hline \multirow{2}{*}{ C-G } & .915 & .915 & .2077 & .2077 & .2077 & .2077 & .915 & .915 & .915 & .2077 & .915 \\
& .09 & .0721 & .915 & .6997 & .7 & .9336 & .09 & .8115 & .5 & .5 & .5 \\
\hline \multirow{2}{*}{ A-B } & .09 & .6997 & .6997 & .3142 & .3142 & .3142 & .09 & .6997 & .09 & .3142 & .3142 \\
& .02438 & .0721 & .2077 & .3142 & .4524 & .5589 & .6997 & .8115 & .9336 & .9841 & .9841 \\
\hline \multirow{2}{*}{ B-C } & .8115 & .7 & .7 & .4524 & .4524 & .4524 & .8115 & .7 & .8115 & .4524 & .4524 \\
& .02438 & .0721 & .2077 & .3142 & .4524 & .5589 & .6997 & .8115 & .9336 & .9841 & .9841 \\
\hline \multirow{2}{*}{ C-A } & .5 & .9336 & .9336 & .5589 & .5589 & .5589 & .5 & .9336 & .5 & .5589 & .5589 \\
& .02438 & .0721 & .2077 & .3142 & .4524 & .5589 & .5 & .8115 & .9336 & .9841 & .9841 \\
\hline \multirow{2}{*}{ AB-G } & .6997 & .09 & .09 & .6997 & .6997 & .6997 & .6997 & .09 & .09 & .6997 & .09 \\
& .09 & .7 & .915 & .09 & .8115 & .5 & .09 & .7 & .9336 & .5 & .5 \\
\hline \multirow{2}{*}{ BC-G } & .7 & .7 & .8115 & .8115 & .8115 & .7 & .8115 & .8115 & .7 & .8115 & .8115 \\
& .09 & .0721 & .915 & .7 & .9336 & .09 & .5 & .5 & .09 & .5589 & .5589 \\
\hline \multirow{2}{*}{ CA-G } & .9336 & .5 & .5 & .9336 & .9336 & .9336 & .9336 & .5 & .9336 & .9336 & .5 \\
& .09 & .7 & .915 & .09 & .8115 & .5 & .09 & .7 & .5 & .5 & .5 \\
\hline \multirow{2}{*}{ ABC } & .5 & .5 & .5 & .9841 & .9841 & .9841 & .5 & 5 & .5 & .9841 & .9841 \\
& .02438 & .0721 & .2077 & .3142 & .4524 & .5589 & .6997 & .8115 & .9336 & .9841 & .9841 \\
\hline \multirow{2}{*}{ ABCG } & .5 & .5 & .5 & .9841 & .9841 & .9841 & .5 & .5 & .5 & .9841 & .9841 \\
& .09 & .7 & .915 & .3142 & .4524 & .5589 & .09 & .8115 & .8115 & .9841 & .9841 \\
\hline
\end{tabular}


Fault Classification on the Basis of Neuro Fuzzy Output Here 0 shows non-fault condition and 1 shows fault-condition

Table 5. Fault Classification

\begin{tabular}{cccccc}
\hline S.No & A & B & C & G & $\begin{array}{c}\text { TYPE OF } \\
\text { FAULT }\end{array}$ \\
\hline 1 & 1 & 0 & 0 & 1 & A-G \\
2 & 0 & 1 & 0 & 1 & B-G \\
3 & 0 & 0 & 1 & 1 & C-G \\
4 & 1 & 1 & 0 & 0 & A-B \\
5 & 0 & 1 & 1 & 0 & B-C \\
6 & 1 & 0 & 1 & 0 & A-C \\
7 & 1 & 1 & 0 & 1 & A-B-G \\
8 & 0 & 1 & 1 & 1 & B-C-G \\
9 & 1 & 0 & 1 & 1 & A-C-G \\
10 & 1 & 1 & 1 & 0 & A-B-C/A-B-C-G \\
\hline
\end{tabular}

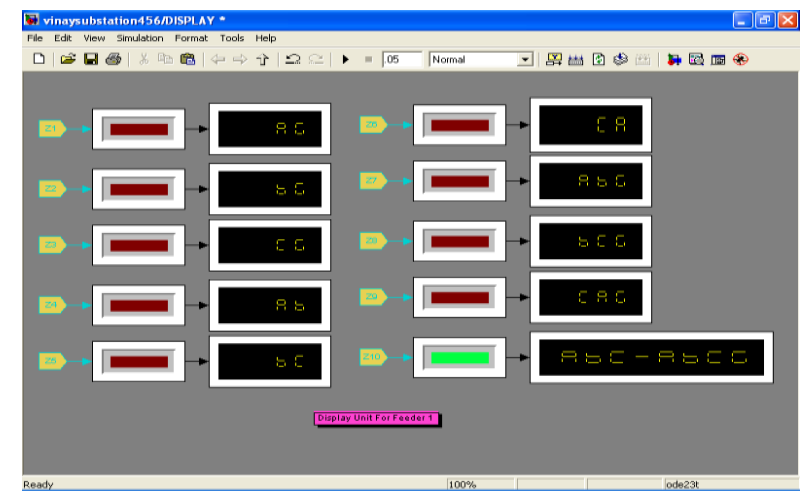

Figure 9. Display for Identification of Fault

\section{CONCLUSION}

In this paper, identification of fault using neuro-fuzzy method has been done in real time. It is proved to be a fast, robust approach as output is in 0,1 form that would perform for various power system condition. Further refinement of neuro-fuzzy model can implement in an real power system to diagnosis of faults. In this paper, neuro-fuzzy technique shows capability of estimating the fault and their types. Ground current can easily distinguish the type of fault occur. We conclude following:

a. Three line and ground current measurements are sufficient to implement this technique

b. Technique is able to identify all types of short circuit faults accurately, at multi-fault condition.

c. The accuracy of this method is very high and not dependent on the type of transients encountered during a fault.

\section{REFERENCE}

[1] Wen-Hui Chen, Chih-Wen Liu And Men-Shen Tsai, "On Line Fault Diagnosis of Distribution Substation Using Hybrid Cause-Effect Network And Fuzzy Ruled-Based Method ," In Proc. IEEE Power Eng. Soc. Winter Meeting, Jan. 2000.

[2] K.K. Li, L.L. Lai, And A.K. David, “Application of Artificial Neural Network In Fault Location Technique,” Int. Journal of Engineering Intelligent Systems, Vol. 1, No. 3, Pp. 226-231, Apr2000.

[3] M. S. Pasand And H. K. Zadeh, "Transmission Line Fault Detection and Phase Selection Using ANN," Int. Conf. on Power System Transient, Pp 1-6, Jan. 2003.

[4] P. K. Dash And S. R. Samantray, "An Accurate Fault Classification Algorithm Using A Minimal Radial Basis Function Neural Network", Published In Engg. Intelligent System, Vol.4, Pp. 205-210, 2004.

[5] P. K. Wong, "Neural Network Applications In Power Systems," Int. Journal of Engineering Intelligent Systems, Vol. 1, No. 3,Pp. 133-158, Dec. 1993.

[6] K. Gayatri And N. Kumarappan, "Comparative Study of Fault Identification and Classification on Ehv Lines Using Discrete Wavelet Transform and Fourier Transform Based Ann,” Int. J. Of Elect. Comp. And System Engg. Vol. 53, No.3, 2008, Pp. 127-136.

[7] M. Pirouti, A. A Fatih And I.B. Sadik, "Fault Identification and Classification for Short Medium Voltage Underground Cable Based On ANN,” Journal Of Electrical Engg.Vol. 59, No. 5,Pp. 272-276, 2008.

[8] A. Bernier, M. D'huzzo, L. Sanson and M. Savastan, "A Neural, Network Approach Foridentification and Fault Diagnosis on Dynamic Systems,” IEEE Trans., Vol. 2 ,No.5, Pp.564-569, 1993

[9] Z. Wang, Yilu Li, P. J. Griffin, N. C. Wang, T. Y. Guo, F. T.C. Huang "“Artificial Intelligence in Power Equipment Fault Diagnosis," IEEE Trans. on Power Deliver, Vol. 3 ,No.8 ,Pp247-252, 2000

[10] Samuel N. Hamilton And Alex Orailoglu, "On-Line Test For Fault-Secure Fault I Dentification,'IEEE Transactions on (VLSI) Systems, Vol. 8, No. 4, Pp. 447-452, August 2000.

[11] Marouf Pirouti, "Neural Network Based Fault Location Estimator for Short Medium Voltage Underground Cable," International Journal of Electrical Power Engg. Vol. 2, No.5, Pp.340-344, 2008.

[12] M. Togami, N. Abe, T. Kitahashi, And H. Ogawa, "On The Application of A Machine Learning Technique to Fault Diagnosis Of Power Distribution Lines,” IEEE Trans. on PWRD, Vol. 10, No. 4, Pp. 1927-1936, 1995.

[13] K.H. Kim And J.K. Park, "Application of Hierarchical Neural Networks to Fault Diagnosis of Power Systems," Electrical Power \& Energy Systems, Vol.15, No. 2, Pp. 65-70, 1993. 
[14] S. Rahman, "Artificial Intelligence in Electric Power Systems: A Survey of The Japanese Industry", IEEE Trans. on Power Systems, Vol. 8 , No. 3, Pp. 1211-2218.

[15] Zadeh L. A., "Fuzzy Sets", Informat. Control, No. 8, 1965, Pp. 338-353.

[16] H. W. Hang, David, "Intelligent System Identifies and Locates Transmission Faults," International Journal of Electrical Power Engg., Vol.3, Pp.201-205, 1997.

[17] K.P. Wong, "Artificial Intelligence and Neural Networks Applications in Power Systems", IEE 2nd International Conference on Advances in Power System Control, Operation and Management, Vol.7, No.10, Pp. 37-46. 1993.

[18] M. Kezunovic, "Intelligent Systems in Protection Engineering”, Power System Technology, Proceedings of Power Conf,Vol. 2, Pp. 801-806. Dec. 2000.

[19] T. Takagi, M. Sugeno, "Fuzzy Identification of Systems And Its Applications to Modeling and Control", IEEE Trans. Sys, Man, Cyber, Vol. SMC-15, 1985, Pp. 116-132.

[20] D. Waikar And F Rahman, "Assessment of Artificial Intelligence Techniques for Power System Protection", Energy Management and Power Delivery, Proceedings Of EMPD, Vol. 2, Pp. 436-441, March 1998.

\section{BIOGRAPHY OF AUTHORS}
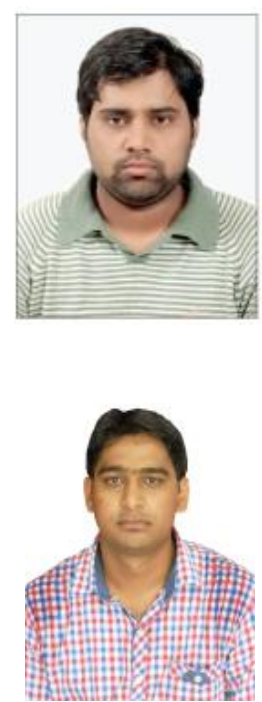

Er.Vinay Kumar Harit received B.Tech Degree in Electrical Engineering from RGE College Meerut, UP (India) in 2007. He has received M.Tech in Electrical Power system Management from Jamia Millia Islamia, Delhi (India) in 2009.He is working as an Junior Engineer in New Delhi Municipal Council at New Delhi since 2009. He is current pursing Ph.D in Electrical Engineering from Delhi Technical University, Delhi. His areas of interest are Power System, Smart Grid, Hybrid Power System, Power Quality. Email:-panchsheelboudh @live.com

Er.Anirudh Yadav received the B.Tech Degree in Electrical Engineering from GBTU, Lucknow (India) in 2012. He has received the M.Tech degree in Electrical Engineering (Power System) from Department of Electrical Engineering, S.H.I.A.T.S, Allahabad, U.P. (India). Email id-er.anirudh53@gmail.com 